\title{
Letramento matemático: um processo construído pelo narrar e pelas linguagens
}

\author{
Cidinéia da Costa Luvison ${ }^{1}$
}

Luzia Batista de Oliveira Silva²

\section{Resumo}

O presente artigo $^{3}$ trata-se de um recorte de uma pesquisa de doutorado defendida no ano de 2017 e que investigou sobre o processo de letramento matemático a partir de narrativas para a apropriação da linguagem e de conceitos matemáticos. Para este texto o objetivo é trazer algumas discussões sobre o letramento em aulas de matemática (Kleiman) e o uso das linguagens enquanto parte do desenvolvimento conceitual pelo aluno (Bakhtin; Ricoeur; e Vigotski). Para isso, foram selecionadas algumas narrativas orais e escritas de alunos do 3o ano do Ensino Fundamental de uma escola pública municipal do interior de São Paulo. Os resultados evidenciaram que o letramento está aliado as práticas sociais, a partir da ação planejada na sala de aula, trazendo a possibilidade do aluno comunicar, ler, narrar e transformar-se.

Palavras-chave: Letramento; Matemática; Narrativa; Elaboração Conceitual.

\section{Mathematical literacy: a process built by narrative and languages}

\begin{abstract}
This study is part of a doctoral research carried out in 2007 that has analyzed students' statements on the process of learning mathematical language and concepts. The goal is to carry out an investigation on the teaching methods and languages used in the classroom (Kleiman) so that the students may understand mathematical concepts (Bakhtin; Ricoeur; e Vigotski). Third-grade students from a public school in the city of São Paulo provided spoken and written statements that were selected for this study. Results showed that the process of acquiring mathematical literacy is linked to social practices and activities that could be performed in schools which have a social culture comprised of an intentional teaching approach to mathematics classes.
\end{abstract}

Keywords: Literacy; Mathematics; Narrative; Conceptual Elaboration.

\section{Introdução}

A linguagem sempre esteve presente nas mais diferentes ações do ser humano. Através dela transmitimos ao outro nossos descontentamentos, expressões de dor, felicidade, interesse, preocupação, incômodo sobre o mundo e o outro. Esses sentimentos são configurados por nossas ações, mediadas pela linguagem. O gesto, o olhar, a fala, a escrita, as expressões artísticas mais variadas, como a música, a dança, a pintura, o teatro, a novela, expressam ações, descrevem

\footnotetext{
${ }^{1}$ Centro Universitário de Itapira - UNIESI, Itapira, e-mail: cidineiadacosta.luvison@gmail.com

2 Universidade São Francisco - USF, Itatiba, e-mail: lubaos@gmail.com

${ }^{3}$ O presente trabalho foi realizado com apoio da Coordenação de Aperfeiçoamento de Pessoal de Nível Superior Brasil (CAPES) - Código de Financiamento 001.
} 
o mundo e a realidade vista e sentida pelo humano, que relaciona a sua vida a sua experiência, narrando, criando e recriando-a a todo momento.

Somos cercados e constituídos pela linguagem e por ela (re)significados a todo o momento, pois estamos imersos no meio social e constantemente vivenciando diferentes situações do dia a dia.

Essas diferentes situações estão constituídas nas práticas sociais em que a criança vai se desenvolvendo ao observar o contexto e dele fazer parte. Ao pensar sobre o ambiente escolar essas ações se ampliam, pois essas práticas serão desenvolvidas em contextos específicos, para objetivos específicos, quando analisamos a escola e o acesso e uso que ela faz da escrita, da leitura, dos conceitos matemáticos e de tantas outras linguagens. Nesse sentido, as práticas e as ações sociais que são aprendidas e apropriadas ao longo da vida são agregadas às experiências partilhadas no ambiente escolar e aos conceitos científicos desenvolvidos especificamente na escola.

É nesse ambiente que a criança possui o acesso aos conceitos científicos e que desenvolvem novas reflexões ao longo do tempo, discutindo e ampliando suas descobertas com um ambiente de aprendizagem intencionalmente planejado e constituído por toda a comunidade escolar, do qual fazem parte alunos, professores, funcionários e outras crianças. A presença desse conjunto de ações, possibilita que as crianças se desenvolvam constantemente e mobilizem-se a refletir sobre o que os cercam a partir de suas experiências e das linguagens que atravessam o espaço escolar. Nesse sentido, é importante pontuar que esse conjunto de ações está relacionada ao letramento e suas funções nas diferentes práticas sociais.

Pensando em todos esses aspectos do uso das diferentes linguagens como parte do processo de letramento e desenvolvimento de conceitos científicos no ambiente escolar nosso objetivo nesse artigo é trazer à tona algumas discussões sobre o letramento nas aulas de matemática, discussões que foram fruto de uma tese de doutorado desenvolvida pela 1a autora sob a orientação da 2a autora. Para investigação tomamos como referência os diários de aprendizagem produzidos pelos alunos do 3 o ano do Ensino Fundamental em uma escola da rede municipal do interior de São Paulo durante as aulas de matemática, na qual era professorapesquisadora.

Nesse texto discutimos inicialmente sobre o letramento e suas especificidades nas aulas 
de matemática. Em seguida, tratamos do protagonismo de alunos a partir de narrativas orais e escritas para o desenvolvimento de conceitos matemáticos a partir de uma cultura de aula de matemática intencionalmente planejada.

\section{Narrativas e letramento(s)}

Pensar sobre o letramento traz inúmeras discussões. Desde a década de 1980 as questões relativas à alfabetização e ao letramento foram desenvolvidas no que tange tanto à língua materna quanto ao letramento matemático, embora as pesquisas que envolviam a língua materna fossem em maior número e maior alcance, pois as políticas públicas em torno do ensinar a ler e a escrever foram mais intensas do que aquelas voltadas à matemática. Bons exemplos foram as formações em serviço promovidas pelas políticas públicas com foco na língua materna; e não posso deixar de mencionar o Programa de Formação de Professores Alfabetizadores $(\text { PROFA })^{4}$, formulado em 2001 pela Secretaria de Ensino Fundamental do Ministério da Educação, que atendeu diversos municípios e, sobremaneira, causou certo "esquecimento" da matemática e da necessidade de formação dos professores nas escolas.

No que se refere à educação matemática, como aponta Nacarato (2013, p.65):

No caso específico da educação matemática, construtos teóricos até então ausentes das discussões começam a ser veiculados: alfabetização matemática, literacia, letramento, numeracia e numeramento. Os termos 'literacia' e 'numeracia' (traduções de literacye numeracy), utilizados em outros países, principalmente de língua portuguesa, foram inseridos no contexto brasileiro como 'letramento' e 'numeramento'.

No entanto, o que predominou nas décadas de 1980 e 1990 foi o conceito de alfabetização matemática - o que representou um avanço curricular, visto que até então não se discutia o papel da linguagem na aprendizagem matemática.

Tomando como base os estudos de Kleiman (1995, 2002, 2005, 2007), observa-se que o letramento não está dissociado das relações contextuais, políticas e ideológicas em que vivemos.

\footnotetext{
4 BRASIL. MEC. Programa de Formação de Professores Alfabetizadores - PROFA. Secretaria de Educação Fundamental. Brasília, DF, 2001. Disponível em: http://portal.mec.gov.br/seb/arquivos/pdf/Profa
}

Periódico Horizontes - USF - Itatiba, SP - Brasil - e020008 
Ao tomar contato com qualquer situação cotidiana, já estamos vivenciando contextos de letramento, em que múltiplas linguagens estão, a todo momento, sendo acionadas.

Nos estudos de Fonseca (2009), referência importante no âmbito da educação matemática, a autora faz uso do termo "numeramento" e estabelece relações de inclusão do numeramento nas práticas de letramento. Ela compreende que, tanto as práticas da cultura escrita quanto as práticas orais de numeramento estão inseridas em práticas de letramento e marcadas pela cultura escrita. Dessa forma, Fonseca (2009, p.55) considera que

tomar práticas de numeramento como práticas de letramento permite-nos ainda valer-nos dos estudos sobre letramento, que contam com uma produção bem mais alentada e amadurecida do que a produção sobre numeramento, no que se refere tanto à elaboração de conceitos e sua mobilização em estudos mais prodigamente replicados e avaliados, quanto à disponibilização de subsídios para a prática pedagógica, forjados a partir de resultados desses estudos.

Certamente, a relevância dos estudos sobre letramento ampliado pelo campo da linguagem se torna um grande subsídio para pensar sobre o campo da matemática e acerca das linguagens e dos conceitos que norteiam essa área do conhecimento, que, além de suas especificidades linguísticas, carrega uma série de relações conceituais e de escrita (registros) para pensar no conhecimento matemático e nos conceitos de alfabetização e letramento, por longo tempo utilizados como dicotômicos. Como menciona Kleiman (2005, p.11), "o letramento não é alfabetização, mas a inclui! Em outras palavras, letramento e alfabetização estão associados".

Assim, alfabetização é uma prática de letramento e faz parte de um conjunto de práticas sociais de usos da escrita realizados no ambiente escolar; por isso, segundo Kleiman (2007), é concretizada em eventos em sala de aula, na instituição escolar e, embora com características específicas, é parte integrante do letramento.

A todo momento estamos imersos em situações cotidianas que envolvem a linguagem, a interação com a escrita, com a oralidade, pois é através da relação com as múltiplas linguagens do nosso cotidiano que nós desenvolvemos e pertencemos a esse universo letrado.

Ao pensar nessas relações, pode-se refletir acerca dessas convergências também no campo da educação matemática. Cotidianamente estamos em contato com situações que envolvem números, dinheiro, quantidades, formas, dados estatísticos, entre tantos outros 
elementos. Ali também estão presentes múltiplas linguagens, ou seja, linguagens matemáticas. Dessa forma, nem sempre situações vivenciadas com as práticas e as experiências do cotidiano no contexto escolar são possíveis fora da escola.

Ao pensar nessas especificidades, o letramento é algo que se entrecruza e se articula com o conhecimento, perpassado pelas linguagens. Linguagens que se fazem presentes como práticas verbais (comunicação) e não verbais (sinais, gestos, expressões faciais, corporais etc.) e como registros (escrita). Linguagens que se entrecruzam com o conhecimento, que estão aliadas com as práticas sociais, contextuais e científicas, por isso a dialogicidade com o letramento. Tomo como base os estudos de Street (2006, p.466):

Prefiro trabalhar com base no que chamo de modelo "ideológico" de letramento, o qual reconhece uma multiplicidade de letramentos; que o significado e os usos das práticas de letramento estão relacionados com contextos culturais específicos; e que essas práticas estão sempre associadas com relações de poder e ideologia: não são simplesmente tecnologias neutras.

Falar da matemática como prática social seria observar os letramentos como uma forma de pertença ao mundo, um pertencimento pelo qual o aluno está diretamente constituído. As relações propostas no ambiente escolar possuem uma proximidade ou, de certa forma, resquícios provenientes do contexto vivido fora da escola. Estar em um ambiente letrado em que os números, os valores, as formas estão presentes associa-se, ao mesmo tempo, à compreensão, à aproximação de uma leitura, que diz ao leitor, que pertence a ele, porque foi apropriado e refletido no ambiente escolar. Não observamos apenas como um processo em que ocorre a aquisição da escrita numérica, matemática, enfim, um "saber-fazer", mas um processo inserido nas práticas de letramento, pois não há como aprender a registrar números, fazer cálculos, resolver problemas e comunicar a seu respeito sem articulá-los com as experiências e as vivências que carregam consigo.

Para Bakhtin (1999, p.73),

a língua, enquanto produto acabado ('ergon'), enquanto sistema estável (léxico, gramática, fonética), apresenta-se como um depósito inerte, tal como a lava fria da criação linguística, abstratamente construída pelos linguistas com vistas à sua aquisição prática como instrumento pronto para ser estudado. 
Estabelecendo uma analogia com os escritos de Bakhtin (1999), compreendemos que esse instrumento pronto, acabado, como uma forma de depósito inerte proposto pelos matemáticos não deve ser concebido quando pensamos nessa construção e apropriação do conhecimento matemático com crianças dos anos iniciais do ensino fundamental. Isso porque compreender todo o processo de escrita e leitura, os estilos da linguagem e da escrita matemática, dotada de simbologias, demanda um processo de construção por parte do aluno, pois não é um ato mecânico de aquisição, de treinos intermináveis para saber: como se opera competentemente; como se escrevem números; como se realizam os cálculos das quatro operações; como se escreve uma sequência numérica; como se atribuem valores e quantidades a um dado objeto; como se nomeiam formas geométricas; ou como se elencam as medidas em determinado espaço ou forma.

Esse contexto de letramentos requer um longo caminho de reflexão acerca do conhecimento matemático, atribuindo significado a cada escrita, operação, nomeação. É preciso, enfim, apropriar-se da leitura-escrita matemática que está imersa em um contexto de números, sinais, códigos e regras de funcionalidades. Para Bakhtin (1999, p.94):

Enquanto uma forma linguística for apenas um sinal e for percebida pelo receptor somente como tal, ela não terá para ele nenhum valor linguístico. A pura "sinalidade" não existe, mesmo nas primeiras fases da aquisição da linguagem. Até mesmo ali, a forma é orientada pelo contexto, já constitui um signo, embora o componente de "sinalidade" e de identificação que the é correlata seja real. Assim, o elemento que torna a forma linguística um signo não é sua identidade como sinal, mas sua mobilidade específica; da mesma forma que aquilo que constitui a descodificação da forma linguística não é o reconhecimento do sinal, mas a compreensão da palavra no seu sentido particular, isto é, a apreensão da orientação que é conferida à palavra por um contexto e uma situação precisos, uma orientação no sentido da evolução e não do imobilismo.

Dessa forma, parte-se do pressuposto de que o letramento, por estar aliado ao conhecimento científico e social, pode estar perpassado por linguagens que carregam suas especificidades, seu estilo, sua marca. Essas especificidades estão cercadas tanto pelo registro quanto pela comunicação, em que a oralidade, "o falar" sobre a matemática, usando conceitos, expressões, requer uma relação discursiva que não está presente em outras áreas. Por isso que a aprendizagem matemática no ambiente escolar precisa ser constituída pelas práticas de 
letramentos, em um processo de elaboração conceitual que se realize através dos letramentos e de sua impregnação mútua com a narrativa.

Talvez esse ambiente seja possibilitado quando a criança tem liberdade e autonomia para narrar suas experiências, compreensões e articulações no aprendizado proposto pela escola, fazendo uso de levantamento de hipóteses, argumentações, analogias, apropriação da escrita e da leitura, aproximação com a linguagem matemática, negociação de significados. E, nesse movimento, o letramento poderá ser um fio condutor para a elaboração conceitual dos alunos no processo de apropriação da linguagem.

O narrar, nas aulas de matemática, liga-se às práticas sociais e se articula ao contexto escolar com o aprendizado dessa escrita numérica, simbólica, com sua leitura e comunicação. Quando as crianças iniciam sua vida escolar, já vêm carregadas de relações criadas em seu contexto familiar e social. A presença dos números, dos símbolos e das quantificações em que está imersa pode favorecer um conjunto de analogias, relações e hipóteses que serão gradualmente desenvolvidas e acrescidas no contexto escolar.

Quando solicito a uma criança que represente quantidades ou que resolva um problema contendo relações de quantificações ou outros conceitos matemáticos, essas comunicações e esses registros, muitas vezes, são realizados a partir de suas vivências dentro e fora da escola. A presença do desenho, por exemplo, é um forte movimento utilizado por elas para fazer seus registros e, ao mesmo tempo, nomeá-los, dando um significado a cada um de seus traços.

Esses desenhos vão ganhando outra dimensão, à medida que a criança vai ocupando espaços de discussões e vivências na sala de aula, tendo o professor como referência de escrita e oralização; e, à medida que discute, apresenta, negocia, registra e lê, possibilita que os repertórios de registro e de discurso se ampliem. As ampliações podem vir aliadas ao reconhecimento, à utilização e à escrita de números no seu contexto diário, ao compor e decompor escritas numéricas para a realização de cálculos convencionais (algoritmos, sentenças matemáticas...) ou não convencionais (estratégias pessoais); a escrita de medidas, de formas geométricas, de códigos e informações, em que gradualmente vão conseguindo propor um significado a esses registros.

Esses significados, acreditamos, vão sendo construídos dialeticamente com a leitura, pois, à medida que os alunos vão construindo e ampliando seus repertórios de escritas matemáticas, 
podem vir a estabelecer nomeações e outras leituras, diante desses símbolos que vão se transformando em signos, os quais serão construídos e apropriados no contexto escolar. Essa leitura, materializada por esses signos e carregada de significados, pode propiciar significações no decorrer das enunciações em sala de aula. Essas enunciações são possibilitadas a partir da negociação de significados, da argumentação; enfim, da narrativa e da elaboração do conhecimento matemático. Assim, "a palavra está presente em todos os atos de compreensão e em todos os atos de interpretação" (BAKHTIN, 1999, p.38).

Acreditamos numa cultura social de sala de aula em que os alunos tenham a possibilidade de refletir sobre as tarefas subsidiadas pela linguagem, que tenham "voz" para potencializar discussões, ouvindo e desafiando nas práticas de investigações matemáticas - de letramentos.

\section{O processo de narrar como parte do ambiente de letramento(s)}

No final de 2014 com uma turma do 3 o ano do Ensino Fundamental, iniciou-se uma sequência de tarefas sobre padrões com o objetivo de envolver desde cedo o Ensino Fundamental com esse conceito e o desenvolvimento do pensamento algébrico.

A "sequência de tarefas" não tem a ideia de um "saber fazer", mas compartilhamos dos pensamentos de Hiebert et al. (1997, p.18, tradução minha) ${ }^{5}$, quando afirma, sobre a natureza das tarefas:

Primeiro, as tarefas devem permitir que os estudantes tratem as situações como problemáticas, como algo sobre o qual eles necessitem pensar mais do que como uma prescrição que eles precisam seguir. Segundo, o problemático nas tarefas deve ser a matemática mais do que outros aspectos da situação. Finalmente, com o intuito de fazer os estudantes trabalharem seriamente na tarefa, ela deve oferecer a eles a chance de usar habilidades e conhecimentos que já possuem. Tarefas que eliminam esses critérios são tarefas que podem deixar para trás esse valor da matemática aos estudantes.

\footnotetext{
${ }^{5}$ First, the tasks must allow the students to treat the situations as problematic, as something they need to think about rather than as a prescription they need to follow. Second, what is problematic about the task should he the mathematics rather than other aspects of the situation. Finally, in order for students to work seriously on the task, it must offer students the chance to use skills and knowledge they already possess. Tasks that lit these criteria are tasks that can leave behind something of mathematical value or students (HIEBERT et al., 1997, p.18).
} 
Assim, além de possibilitar momentos nos quais os alunos refletem sobre suas experiências, a sequência de tarefas mobiliza o contato com situações problemáticas em que podem argumentar, investigar, envolver-se na busca de atingir os objetivos. Trabalhar com sequência de tarefas que envolvam determinados conceitos matemáticos faz com que os alunos entrem em contato com diversas situações nas quais esses conceitos estão presentes e possam através deles conjecturar, fazer analogias, analisar diferentes possibilidades, generalizar e validar suas hipóteses. E é nesse momento que estão imersos em um espaço de atividades matemáticas. Esse contexto é garantido, quando

[...] esse espaço seja um ambiente de aprendizagem pautado no diálogo; nas interações; na centralidade do papel do professor; na intencionalidade do ato pedagógico; na proposição de tarefas que motivem os alunos, mobilizando-os para a atividade matemática. Um espaço assim concebido rompe com os modelos de culturas sociais de aula de matemática e coloca os alunos e o professor como protagonistas do processo de produção de saberes matemáticos. Saberes que vão sendo construídos em diferentes níveis de generalidade e vão possibilitando que os alunos sejam capazes de matematizar, independentemente da faixa etária (NACARATO; LUVISON, 2015, p.38-39).

Esse ambiente, que possui como centralidade a ação do professor e do aluno, que, juntos, compartilham e seguem em direção a objetivos comuns, faz voltar ao aspecto da atividade. Estar em atividade representa "estar em ação", uma ação que mobiliza a criança a refletir, a estabelecer relações, a duvidar, argumentar, trocar e significar. Estar em ação representa fazer parte, inserir-se em um ambiente que favoreça a problematização; e, nesse processo, as múltiplas linguagens estão presentes de forma intensa e pulsante. A atividade representa deslocar-se a partir da tarefa proposta a um espaço de negociação de significados em que os gestos, as palavras, os olhares, a escrita, a leitura e tantas outras expressões estão em constante conexão, favorecendo o aprendizado sobre a elaboração conceitual, pois "[...] os conceitos científicos não são assimilados nem decorados pela criança, não são memorizados mas surgem e se constituem por meio de uma imensa tensão de toda a atividade do seu próprio pensamento" (VIGOTSKI, 2009, p.260).

Essa tensão está aliada ao ato de pensamento e, consequentemente, aos atos de linguagem. É pela linguagem que a criança tem a possibilidade de aprender, de comunicar-se, de 
refletir, de reviver as suas experiências e, a partir delas, ressignificar suas compreensões. É através da linguagem que uma tarefa matemática, estática, pode ganhar movimento, ação, pela atividade do pensamento da criança, que também não se constitui de forma unicamente solitária, mas pela ação do e com o outro, das vivências e experiências desse outro, ou seja, somos constituídos pelas e nas relações sociais. Dessa forma,

[...] não se trata de fazer do outro um simples mediador instrumental, particularmente no caso da criança cujo desenvolvimento estaria irremediavelmente comprometido sem a presença prestimosa e a ajuda constante do outro. A mediação do outro tem um sentido muito mais profundo, fazendo dele a condição desse desenvolvimento (SIRGADO, 2000, p.65, grifo do autor).

O aprendizado da criança, em especial, é algo que merece muita atenção. Por se tratar de um ser humano em constante formação e transformação, cercado de imaginação e criatividade, garantir momentos em que a mediação, a reflexão, a narrativa, as problematizações em aulas de matemática sejam viabilizadas faz com que as crianças pertençam (RICOEUR, 1989) ao ambiente escolar e caminhem gradualmente em direção aos conhecimentos científicos, processo que se dá de forma complexa, gradual e no decorrer de toda a escolarização. Por isso é importante garantir desde cedo momentos de reflexão e problematização nas aulas de matemática.

A tarefa sobre os padrões geométricos tinha esses objetivos. Além disso, que buscassem e identificassem a regularidade na sequência, estabelecendo relações entre a forma, a cor e a sua posição, e também que avançassem em relação a outras tarefas já desenvolvidas com a turma sobre regularidades. A tarefa ficou organizada da seguinte forma: 


\section{Tarefa: Padrões geométricos}

\section{Tarefa 1:}

1) Observe as imagens abaixo. O seu desafio é descobrir qual é o padrão.

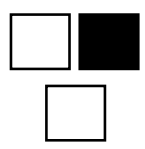

Termo 1

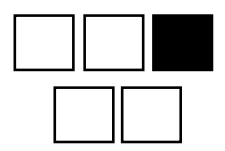

Termo 2

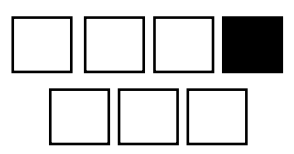

Termo 3

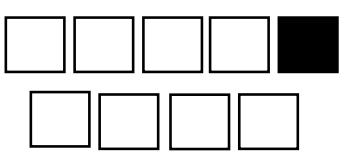

Termo 4

a) Essa sequência tem um segredo. Você já descobriu qual é? Conte suas descobertas.

b) Agora que já descobriu o segredo, o desafio é: desenhe abaixo como ficaria a próxima figura, o termo 5 .

c) E como ficaria o 10.o termo? Desenhe:

d) Como você descobriu?

\section{Tarefa 2:}

No ano passado, com a turma do 3. . ano fizemos algumas tarefas sobre padrões. A aluna Monique também descobriu vários segredos sobre a sequência que estamos investigando. Ela desenhou o 8. termo da seguinte forma, vejam:

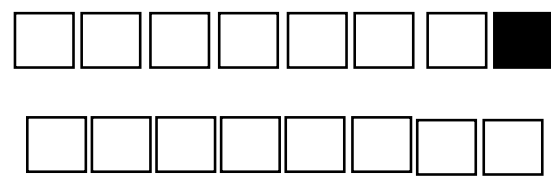

Termo 8

a) Ao explicar para a sala, várias dúvidas surgiram. O que acham que pode ter acontecido? ${ }^{6}$

É importante relembrar que a tarefa é um dos elos que conduz a todo o ciclo do ambiente de investigações matemáticas, porém ela, por si só, não possibilita que a dialética proposta em sala de aula aconteça - é preciso garantir que a comunicação de ideias, a mobilização entre falar, escrever, expressar, narrar seja viabilizada e que a escuta atenta dessas narrativas possibilite a ação do leitor que reflete, comunica, reescreve, diz - enfim, se

\footnotetext{
${ }^{6}$ Essa tarefa foi analisada pelo Grucomat e seus participantes concluíram tratar-se de uma sequência recursiva crescente. Como os alunos trabalham simultaneamente com sequências repetitivas e recursivas, há a possibilidade de que eles interpretem ser repetitiva e que o termo 5 volte a repetir o termo 1.
} 
permite renarrar (reconfigurar - mimese III). E, através desse movimento, garantir que as crianças tenham a possibilidade de construir saberes em diferentes níveis de generalidade e construam com a área relações que não são estritamente prescritivas e reduzidas a listas de exercícios e algoritmos. As crianças têm muito a dizer, a rememorar, pois a narrativa traz "a possibilidade de se voltar para uma lembrança e de nela visar às expectativas que foram realizadas (ou não) ulteriormente contribui para a inserção da lembrança no fluxo unitário da vivência" (RICOEUR, 1997, p.59).

No dia 31 de março de 2014 os alunos estavam organizados em duplas, como geralmente ocorre em todas as aulas, mas a preocupação estava em possibilitar esse momento também para aqueles que ainda não eram alfabetizados; por isso colocá-los com crianças que propiciariam que essa troca ocorresse.

A organização das duplas e dos trios estava pautada na disponibilidade, na paciência, no questionamento que essas crianças poderiam possibilitar a Adriano, Carlos, Jaqueline e Natália7. Precisava, sobremaneira, de alunos questionadores e, ao mesmo tempo, que dessem espaço, respeitassem o tempo de aprendizagem que essas crianças tinham à sua disposição para participar e pertencer a esse grupo. Nesse sentido, não se tratava apenas de selecionar duplas que se sobressaíssem ou não nas aulas de matemática, mas, principalmente, de propiciar a eles momentos nos quais seriam ouvidos, participariam efetivamente. $E$ essa escolha foi extremamente positiva no decorrer da tarefa.

Assim que as cópias das tarefas foram entregues aos alunos, Rafael me chamou para conversar e destacou: "Prô, é parecida com aquela que fizemos do colar!". Percebo nesse instante que Rafael estava estabelecendo relações com a tarefa anterior, do colar de contas que já havíamos feito, mas a minha dúvida seria se realmente estava relacionando com o modelo de repetição apresentado na tarefa ou se o que lhe chamava atenção seria a sua organização, que, embora não fosse igual, trazia em sua linguagem as palavras "padrão" e "segredo", e ao mesmo tempo, a ideia de crescimento e repetição.

Ao questioná-lo sobre o que acreditava que havia de comum entre elas, o aluno disse que "é um padrão, vai repetindo ó" (enquanto apontava com o dedo indicador cada um dos termos

\footnotetext{
${ }^{7}$ Os nomes dos alunos utilizados no decorrer do texto são fictícios.
} 
presentes na tarefa), mas agora temos que descobrir o segredo". Insisti, perguntando se conseguiriam me dizer qual seria ele. Foi quando Rafael ficou pensativo, olhou para cima, fez gestos com a boca, olhou em minha direção e explicou: "Prô, já vi que tem, mas não sei dizer ainda. Eu e o Alexandre temos que investigar para ver se é igual o colar de contas, pode ser ímpar e par, mas é melhor pensar mais, pode ser um segredo difícil...". Ao mencionar as palavras "padrão", "repetindo", estavam fazendo associações, relacionando, à palavra, a própria vinculação de sua origem.

Além disso, nesse momento, a tarefa não significava apenas uma resolução a ser executada, mas para Rafael e Alexandre representava, além disso, um "segredo" a ser descoberto e desvendado. A ação principalmente de Rafael de sinalizar as relações entre as tarefas já propunha alguns indícios de que havia uma suposição de que os padrões possuem uma repetição e que estes são progressivamente ampliados.

As linguagens presentes nesse momento (a partir das imagens e dos escritos da própria tarefa, das enunciações de Rafael), juntamente com seus gestos - de apontar, termo por termo, de movimentar os lábios, de olhar... - , formavam um todo, que buscava, nas suas experiências com outras tarefas, estabelecer relações, criar analogias e aproximações para encontrar sentidos para a nova tarefa. Quantas composições podiam ser visualizadas nesse processo!

Embora fizesse algumas intervenções pontuais quanto ao entendimento das questões, trocando algumas ideias com as crianças e questionando-as, ficaram à vontade para discutir, registrar, estabelecer analogias e conjecturar sobre suas reflexões. Esse momento precisava ser compartilhado, vivenciado entre eles, pois o objetivo seria ampliar essas relações no decorrer da socialização.

Durante o registro, algumas hipóteses já começam a ser lançadas. Rafael e Alexandre, por exemplo, ao analisarem se o padrão possuía algum segredo, destacaram que 
a) Esse padrão tem um segredo. Você já descobriu qual é? Conte suas descobertas.

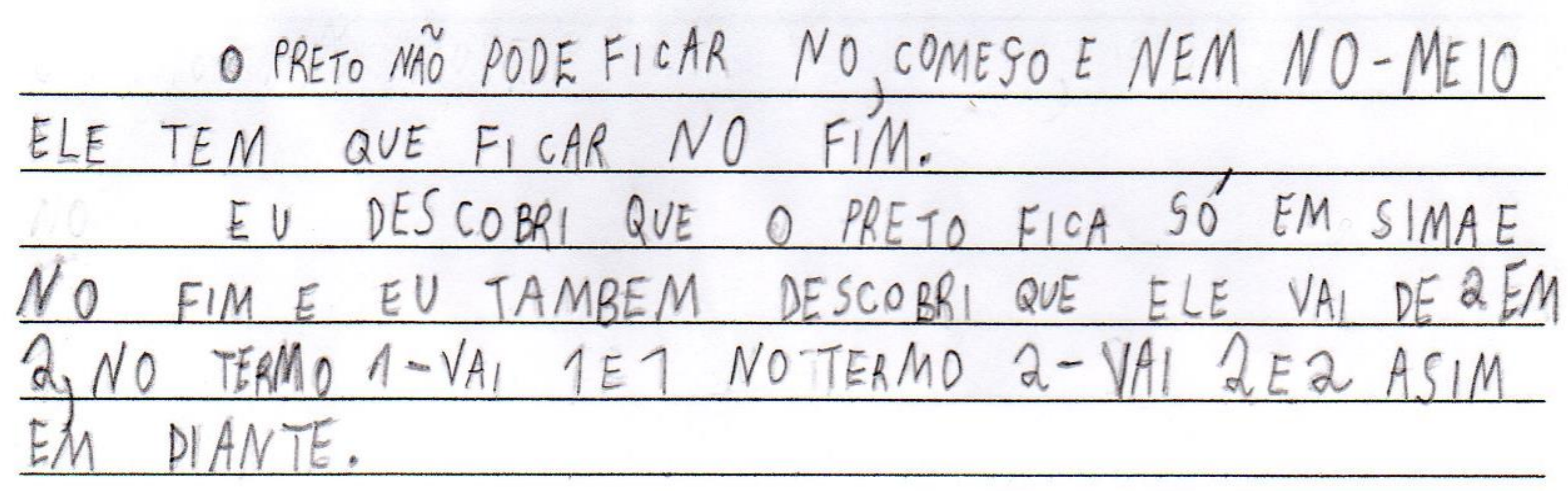

Fonte: acervo da professora-pesquisadora

Rafael e Alexandre percebem que os quadrados brancos, tanto em cima quanto embaixo, aumentavam progressivamente, como enfatizam em seus registros (Figura 1): "ele vai de 2 em 2, no termo 1 vai de 1 em 1 e no termo 2 vai de 2 em 2 assim em diante". De maneira geral, suas primeiras hipóteses explicitam que havia uma sequência de 2 em 2, "isolam" o quadrado preto e observavam esse aumento progressivo nos quadrados brancos. Além disso, demarcam que o termo 1 seria o ponto de partida, quando afirmam que "vai de 1 em 1" no primeiro termo.

Outro registro que chamou a atenção foi o dos alunos Gustavo e Jaqueline, por vários aspectos. Primeiramente, além de Gustavo conseguir auxiliar Jaqueline em suas reflexões, deixando-a participar e integrar-se nas discussões, ele ainda a incentivava no registro, embora sabendo que ela ainda não conseguia ler e escrever. A sua forma de fazê-la participar era através da soletração de palavras e de sua leitura. Muitas vezes Gustavo pede a Jaqueline: "O que você quer escrever sobre a tarefa? Fala e eu vou dizendo as letras pra você escrever". Uma relação que consideramos de fluidez, respeito e cercada de função social, cumplicidade e parceria; ou seja, ele a auxiliava na transformação de sua fala em escrita. Uma relação significativa, pois era feita

\footnotetext{
${ }^{8}$ Transcrição: “O preto não pode ficar no, começo e nem no - meio ele tem que ficar no fim.

Eu descobri que o preto fica só em sima e no fim e eu também descobri que ele vai de 2 em 2, no termo 1 - vai 1 e 1 no termo 2 - vai de 2 e 2 asim em diante".
} 
a partir de uma tarefa, de uma investigação que estavam realizando e revelava uma troca respeitosa entre as crianças. Isso fica evidente no registro seguinte, na Figura 2, em que a escrita de Jaqueline aparece totalmente integrada com a de Gustavo: as marcas desse processo de soletração deixaram evidências, rastros - ora ele escrevia, ora soletrava para que Jaqueline conseguisse de alguma forma deixar sua marca nesses registros. Uma escrita permeada por dois autores, que se cruzam, se entremeiam, se completam...

Autores que, permeados pelo movimento de prefiguração, conseguem configurar, deixar suas marcas, pertencer a esse espaço-tempo, dando forma e extensão à experiência vivida, atribuindo sentidos aos atos (RICOEUR, 1994). Autores que, entremeados por uma responsividade, veem no outro a extensão dessa configuração, cercada por dialogismo, linguagens que perpassam por eles - são ações! Ações do autor-leitor-ouvinte.

Figura 2 - Registro dos alunos Jaqueline e Gustavo ${ }^{9}$

a) Esse padrão tem um segredo. Você já descobriu qual é? Conte suas descobertas.

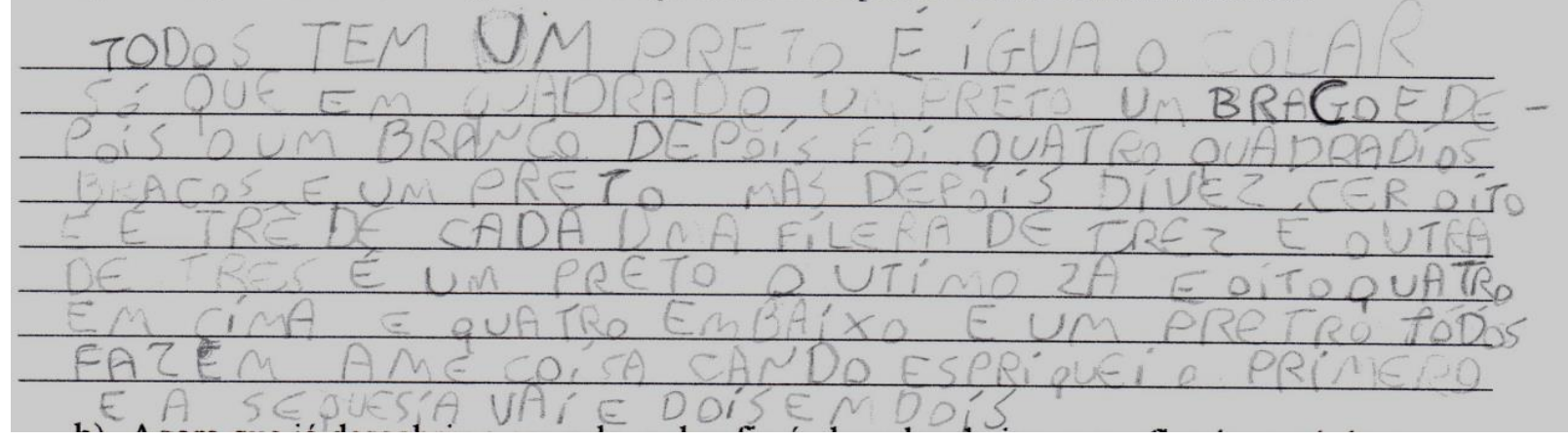

Fonte: acervo da professora-pesquisadora

Os alunos chamam atenção (Figura 2) quando dizem "todos fazem a mesma coisa" para a relação de regularidade do padrão. Narram como os padrões vão sendo formados quando explicam que seria "uma fileira de três e outra de três e um preto, o último já é oito (a soma dos quadradinhos brancos presentes no termo 4) quatro em cima e quatro embaixo e um preto". Essa relação de continuidade dos quadradinhos brancos com o termo foi algo que se tornou

\footnotetext{
${ }^{9}$ Transcrição: "Todos tem um preto é igua o colar só que em quadrado um preto um braco e depois um branco depois foi quatro quadradios bracos e um preto mas depois deve cer oito e é trê de cada uma filera de trêz e outra de tres é um preto o utimo já é oito quatro em cima e quatro embaixo e um pretro todos fazem a mesma coisa cando espriquei o primeiro e a sequêsia vai em dois em dois".
} 
muito significativo para eles, pois a estratégia que encontraram foi isolar o preto e trabalhar apenas com os quadradinhos brancos, porém, não o esquecendo. Ações que vão trazendo sentidos para a composição desses termos, que os fazem expressar de diferentes formas, assumir posicionamentos e voltar aos termos para enriquecer suas hipóteses.

Wilson e Carlos procuraram detalhar um pouco mais seus escritos (Figura 3) e explicar porque observavam esse crescimento de 2 em 2 que outros alunos também defendiam:

Figura 3 - Registro dos alunos Wilson e Carlos $^{10}$

a) Esse padrão tem um segredo. Você já descobriu qual ê? Conte suas descobertas.

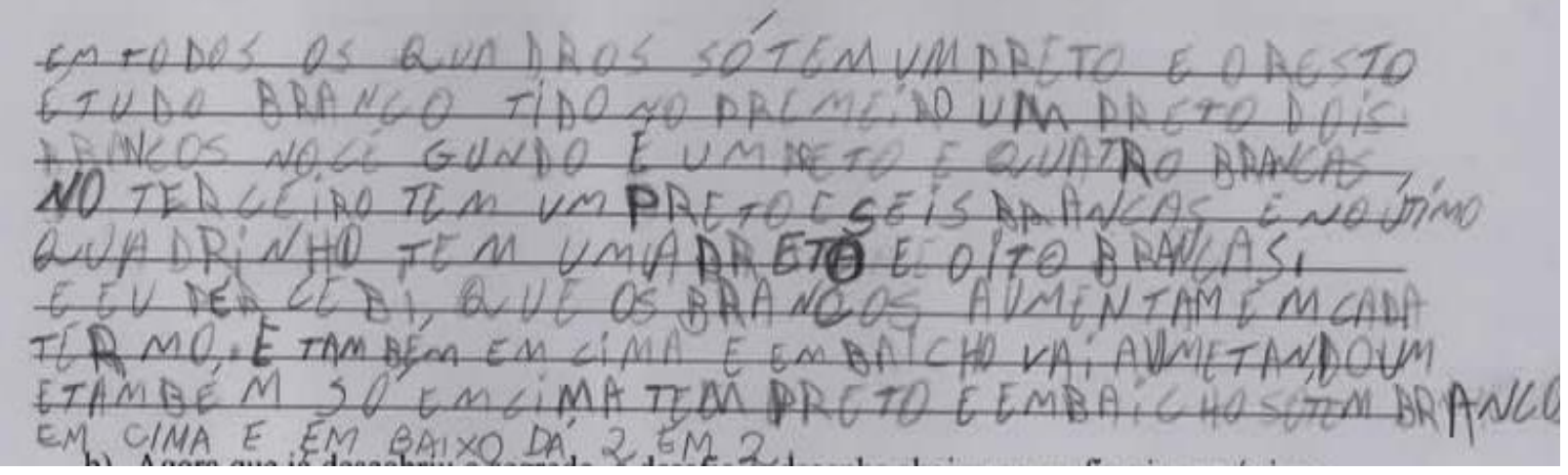

Fonte: acervo da professora-pesquisadora

Além de relatarem o que vai ocorrendo termo a termo, os alunos procuram justificar que o padrão vai aumentando de 2 em 2. Para eles, o aumento progressivo se justifica porque "em cima e embaixo vai aumentando um e também só em cima tem preto e embaixo só tem brancos. Em cima e embaixo dá 2 em 2". Essa compreensão se deve à relação que principalmente Wilson foi estabelecendo com os termos. No decorrer da realização da tarefa, ele apontava com os dedos os últimos quadrados brancos de cada termo, afirmando que no 1 havia 1 e 1, pois era, dizia ele, "o início de tudo". Já no termo 2 havia uma mudança com o aumento de dois quadradinhos, pois tinha 1 a mais em cima e 1 a mais embaixo. No termo 3, da mesma forma, 1 em cima e 1 embaixo e assim sucessivamente, ou seja, isso justificaria, segundo ele, o padrão ir

\footnotetext{
10 Transcrição: "Em todos os quadros só tem um preto e o resto é tudo branco tipo no primeiro um preto dois brancos e no cegundo é um preto e quatro brancas no terceiro tem um preto e seis brancas e no útimo quadrinho tem um preto e oito brancas. E eu percebi que os brancos aumentam em cada termo. E também em cima e embaicho vai aumetando um e também só em cima tem preto e embaicho só tem brancos. Em cima e em baixo dá 2 em 2".
} 
aumentando de 2 em 2.

Também não poderíamos deixar de mencionar as marcas da autoria no texto. Da mesma forma que Wilson dizia tão enfaticamente sobre essa relação que havia percebido sobre a sequência 2 em 2, na escrita isso se torna evidente e marcante quando narra: "E eu percebi que os brancos aumentam em cada termo". Quem seria esse "eu" que o autor demarca em sua escrita? Wilson procurou, no ato de sua fala, explicitar suas inquietudes quanto às suas hipóteses matemáticas, mas também, num ato responsivo com esses escritos, buscou deixar esse rastro, que, muito além de enunciações, se compunha de narrativas demarcadas pelas suas mãos e pela sua voz. Vozes que se entrecruzam e se misturam novamente, tal qual na narrativa de Gustavo e Jaqueline, e, embora explicitassem outros sentimentos, emoções e experiências, mostraram de forma efêmera o seu percurso de reflexões. Uma fala que se torna escrita, uma ação que se torna texto... Há um pertencimento entre as crianças. Suas reflexões não são solitárias, mas produzidas nesse ambiente de investigações, nas experiências que construíram juntos, cada fala, cada gesto, cada expressão, cada registro, cada leitura está constituída por um todo, que vai ora se aproximando, ora se distanciando do processo de configuração. Nesse instante, lembro-me de Pereira (2013, p.183), ao referir-se aos pensamentos ricoeurianos:

[...] o ato de se recordar tem lugar através de uma pequena história interior que nós contamos a nós mesmos, isto é, para nos recordarmos tornamo-nos os interlocutores de nós próprios, através de uma narração, que acontece no foro interior. A este primeiro aspeto acrescenta-se um outro. Para que essa narração seja possível é preciso uma língua, habitualmente a nossa língua materna, ou então uma língua de adoção. E é assim, como podemos constatar, que o elemento social se integra numa narrativa pessoal e interior. Logo, passamos para o lado social, público ou coletivo.

Uma narração que ocorre num foro interior, que faz uso de uma língua materna, que integra uma tríade com o elemento social, pessoal e interior.

No mesmo dia, 30 de março de 2014, iniciaram as socializações. Os alunos não apresentaram dificuldades na realização dessa tarefa, que ocorreu entre eles de forma rápida, pois quando as folhas foram entregues, rememoravam a tarefa do colar de contas e buscavam estabelecer relações entre ela e a nova proposta. Encontrar o "segredo" despertou nas crianças ações e mobilizações para suas reflexões. Assim, era hora de colocá-los a dialogar no ambiente coletivo. 
Embora pareça uma tarefa fácil, nem sempre é simples falar a respeito de nossas reflexões. As crianças não estavam acostumadas com uma cultura social de aula de matemática em que o foco está na reflexão, no diálogo, no levantamento de hipóteses e conjecturas, no dizer acerca do conhecimento matemático. Essa é uma caminhada que precisa ser construída com os alunos, estimulada e ensinada pelo professor. Ao falar a respeito do posicionamento das duplas e dos trios acerca das primeiras hipóteses, era preciso intermediar as falas, debater, interrogar, estimular, perguntar sobre os "porquês" de determinado posicionamento, propor outras reflexões que os levassem a avançar em seus pensamentos ou mesmo "ir além" da tarefa proposta, criando problematizações que os mobilizassem a pensar, refletir, enfim, que os desestabilizassem, rumando a uma ação.

Segundo Hiebert et al. (1997), a compreensão desenvolve-se à medida que refletimos e nos comunicamos com os outros, e as tarefas são fios condutores para que esse processo possa tornar-se parte das aulas de matemática. Para o autor, comunicar significa falar e ouvir, compartilhar o método que se desenvolveu e, ao mesmo tempo, refletir sobre os questionamentos propostos. Porém, para refletir e comunicar, é necessário que tenham "algo de valor" a comunicar, ou seja, os alunos precisam tomar a tarefa "para si", definir metas de resolução de problemas, envolver-se pela situação intrigante que a matemática oferece, o que desperta a imaginação e a criatividade, processos fundamentais "para o pensamento abstrato, para a formação de conceitos" (VIGOTSKI, 2014, p.26).

Essa dialética proposta no ambiente de investigações matemáticas possibilita que a prática de narrar a respeito de suas inquietudes, conjecturando e estabelecendo relações com suas vozes e a dos outros, possa contribuir para a aprendizagem com significado pelos alunos. À medida que dizem, escutam, expressam sentimentos, sensações e têm condições de narrar, podem pensar a respeito da palavra. O significado da palavra é viabilizado quando constroem juntos aproximações, debates e levantamento de hipóteses em sala de aula.

O primeiro episódio que chamou a atenção foi quanto ao segredo que envolviam os termos:

Episódio 1: "Que segredos possuem os termos?" - no primeiro episódio os alunos buscam negociar ideias a fim encontrar uma regularidade entre os termos.

Gustavo: Todos aqui têm um preto igual do colar (pega a folha e começa a apontar para cada um dos termos, acredito que tentando relacionar o padrão 
geométrico ao colar de contas. Nesse momento percebe que essa relação só seria possível ao pensar na sequência do padrão geométrico), só que no colar era um azul e outro vermelho e aqui não tem nem azul nem vermelho, ai é a mesma coisa do colar. No colar era 1 vermelho, 2 azuis e aqui vai de 2 em 2, vai trocando.

Cid: Deixe eu ver se entendi, em cada termo você está me dizendo que vai indo de 2 em 2, seria isso?

Gustavo: Por exemplo, como ficaria o termo 10? Fiz 10 em cima e 1 preto e 10 em baixo aí eu resolvi pensar a partir dos outros, é assim: ao pedir para fazer o desenho eu gravei na mente (busca como recurso as três folhas das tarefas, tentando relacionar o termo quatro, o cinco e também o 10. Conforme narra suas hipóteses, mostra com o dedo indicador esses três termos do padrão e, ao mesmo tempo, desliza-o na folha da esquerda para direita) como que fazia o 10, porque aqui no quarto termo todos os quadradinhos, têm 4 e depois o preto aí nessa tarefa eu fiz todos os quadradinhos 10 e depois o preto.

Cid: Entendi; e você viu que vai até o termo 4, não é? E você falou que foi observando pra conseguir montar os outros termos, então como é que ficou $o$ termo 5?

Gustavo: O termo 5 eu fiz 5 em cima, quadradinho preto e cinco embaixo.

Cid: E vocês? Fizeram diferente do Gustavo, pensaram de forma parecida, alguém gostaria de falar?

Antonio: Eu quero.

Cid: Pode falar, Antonio, você fez igual do Gustavo com 5 brancos e um preto e 5 brancos embaixo ou você pensou diferente?

Antonio: Eu pensei diferente. Tem três quadradinhos, aí comecei a contar no dedo (nesse momento utiliza as mãos e a contagem nos dedos para justificar o que havia pensado) como eu fui descobrindo; aí eu fui anotando aqui.

Cid: Certo, mas quanto você colocou na sua tarefa no termo 5? Você colocou quantos em cima e quantos embaixo? Nesse caso seria esse daqui (indiquei na folha de Antonio a representação que fez), quanto você colocou em cima e quanto você colocou embaixo?

Antonio: Em cima 5.

Cid: Contando com o preto ou sem o preto?

Antonio: Contando com o preto (olha para mim e também ao redor, para os colegas, sorri, abaixa a cabeça, já mostrando certa insegurança, balança seguidamente as pernas), e embaixo 6.

Cid: Então você colocou 5 em cima, contando com o preto, seriam então 4 brancos e 1 preto e embaixo 6 brancos, seria isso? Pessoal e o que vocês acham, o Gustavo colocou 5 brancos e um preto e embaixo 5 brancos, o Antonio colocou 4 brancos e 1 preto e embaixo 6 brancos e agora, qual será a sequência?

Joaquim: Eu e a Tânia colocamos assim ó: "o mesmo quadradinho pintado de preto na direita e os quadrados pintados de branco vão aumentando de 2 em 2, mas o primeiro quadradinho tem um segredo que é em 2 em 2 porque eu e meu colega de classe descobrimos que o primeiro quadrado tem um segredo que os outros não tem", ele faz começar todo o segredo, né?!

Cid: Olha o que o Joaquim e a Tânia trazem de mais uma contribuição para gente. $O$ Joaquim e a Tânia disseram que vai aumentando de 2 em 2 entre $o$ termo 1, termo 2, termo 3 e termo 4, aumenta dois, vai de dois em dois, alguém tinha pensado nisso?

Periódico Horizontes - USF - Itatiba, SP - Brasil - e020008 
$[\ldots]$

Alexandre: Eu fiz igual ao Gustavo (olha para folha e começa a apontar com o dedo para me explicar os caminhos que havia feito): 5 brancos $e 1$ preto $e$ embaixo 5 brancos e aqui (aponta para a folha, mostrando a sequência dos termos) em cima vai de 2 em 2 até chegar no termo 4. Essa aqui eu coloquei 10 brancos e 1 preto e embaixo coloquei 10 brancos.

Cid: O Joaquim, o Gustavo, o Antonio colocam que são 5 brancos em cima e 1 preto e 5 brancos embaixo, e o Antonio colocou 4 brancos em cima e 1 preto e 6 brancos embaixo. E agora?

Wilson: Eu fiz igual o do Gustavo.

Cid: E agora? Como faremos para descobrir sobre a questão do Antonio e do Gustavo? É 6 embaixo e 4 em cima ou não? Como é que fica?

Joaquim: Não é.

Cid: Por que não é, Joaquim?

Joaquim: Por que a quantidade muda, tem que ser 5 embaixo e 5 em cima.

Cid: Por que, Joaquim? Como é a sequência desde o termo 1?

Washingthon: Vai indo de $2 \mathrm{em} 2$.

Gustavo:Tá pedindo aqui os termos. É 5 em cima (mostrando 5 dedos nas mãos e erguendo a mão para indicar em cima) e 5 embaixo (mostra novamente os cinco dedos e coloca a mão abaixo) porque é o termo 5, fica 5 em cima, 5 embaixo e não pode esquecer do preto em cima.

Cid: E a mesma coisa vai acontecer no termo 10, Gustavo?

Gustavo: Sim, a mesma coisa porque tá pedindo o termo 10, tem como tirar (mostra a folha para mim, aponta com o dedo indicador na representação feita sobre o termo 10), vai ser 10 em cima e 10 embaixo, e o preto sempre vai aparecer em cima.

Cid: Pessoal, vocês escutaram o que o Gustavo falou? Disse que como é termo 10, é 10 em cima, 10 embaixo e tem o preto; e se fosse outro número? O termo 12 ?

Gustavo: Se fosse o 12 ia ser 12 em cima, 12 embaixo e o preto.

Cid: $O$ que vocês acham?

Rafael: Eu acho que não.

Cid: $E$ por que não, Rafael? (Nesse momento Alexandre pega as folhas das tarefas e as coloca na direção de Rafael, dá dois tapas na folha e chama a sua atenção para perceber que os termos iam aumentando e havia relação entre o termo e o número de quadradinhos brancos, que era a defesa de Gustavo desde o início. O objetivo de Alexandre era convencer o colega que a ideia seria essa.) (grifo nosso).

Nesse primeiro episódio, o que chama mais atenção é a relação que eles estabelecem entre a tarefa e os sentidos que vão atribuindo a ela. No decorrer da socialização, Gustavo busca estabelecer relações com a tarefa do colar de contas. Ele necessitava inicialmente expor justificativas para a regularidade, embora em seus dizeres não conseguisse expressar em palavras a relação existente entre as duas tarefas; por isso, tenta recorrer a aproximações e exemplos que traziam, de certa forma, algumas semelhanças. Esses sentidos que vão sendo 
atribuídos no decorrer da socialização são aproximações que as crianças encontram para dizer sobre a palavra. Mesmo não conseguindo expressar, comunicavam-se, aproximavam-se do significado, dialogavam com os colegas e comigo, tentando justificar as suas hipóteses, encontrar caminhos para justificar suas afirmações...

É importante destacar que Gustavo foi o primeiro a levantar hipóteses em relação ao fato de a sequência ocorrer de 2 em 2 . O aluno procurava encontrar uma forma para validar o que estava entendendo por essa regularidade. Foi quando integrou ao nosso diálogo o exemplo do termo 10, justificando, de posse de seus registros, como isso ocorria e de que forma poderia ser representado, pois, embora não falasse a respeito do termo 5, também estava com as folhas em mãos, na tentativa de me convencer de que essa sequência estava ocorrendo efetivamente de 2 em 2. Apontou para os termos (Figura 4), enfatizando os dois últimos quadradinhos de cada sequência:

Figura 4 - Registro do aluno Gustavo

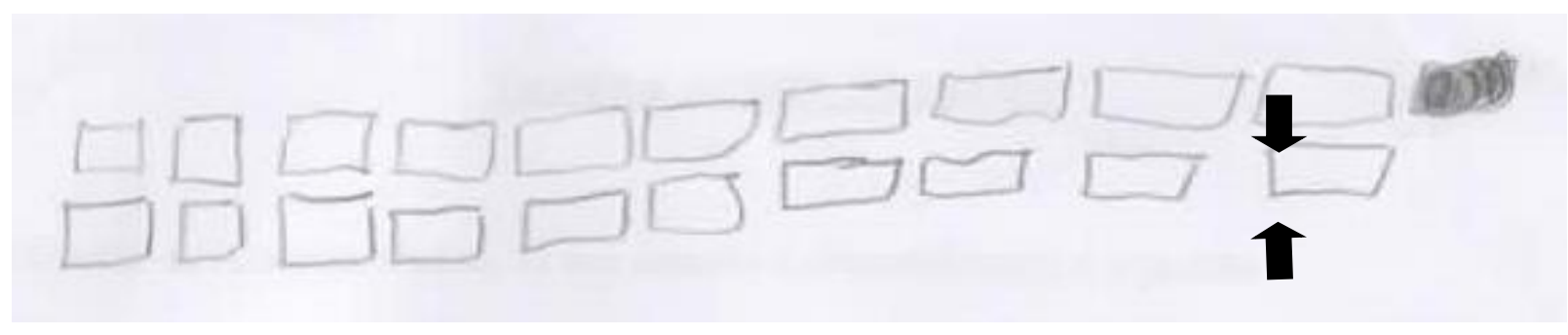

Fonte: acervo da professora-pesquisadora

Isso faz recordar dos registros de Wilson, que menciona: "[...] em cima e embaixo vai aumentando um e também só em cima tem preto e embaixo só tem brancos. Em cima e embaixo dá 2 em 2". Ambos refletem sobre o mesmo ponto, porém Wilson utiliza de seus escritos para reforçar esse aspecto, enquanto Gustavo em momento algum o mencionou no registro, mas os pontuou no instante da fala, talvez porque não fosse significativo naquele momento escrever ou, ainda, só se tivesse dado conta disso no decorrer da socialização, nas vivências com o grupo...

A possibilidade de outra hipótese, no caso de Antonio, não desestabilizou o grupo. Talvez o questionamento realizado elaborando um novo desafio a partir do registro de Antonio, tenha fortalecido e estimulado Joaquim a reforçar a sequência de 2 em 2 e, ao mesmo tempo, a considerar a hipótese de que "o primeiro quadrado tem um segredo que os outros não tem, ele 
faz começar todo o segredo né!", já que compreendia que todo o percurso iniciaria a partir dele. Gustavo ainda faz a relação com a palavra "termo 5", quando justifica que seriam 5 brancos em cima e um preto e 5 brancos embaixo, pois, como se tratava do termo 5, havia relação da palavra "termo 5"com a organização da sequência, além do que, procurava "isolar" o preto e criar um processo de generalização, que ocorreu quando questionado sobre o termo 12.

Nesse momento, é possível perceber o quanto as crianças utilizam a linguagem nesse processo de ação. As negociações de significados que vão estabelecendo com os seus registros, na interlocução com outros alunos e comigo, pelas palavras proferidas nesse ambiente de comunicação matemática vão possibilitando novas relações, novos pensares. E propiciam que narrem a respeito de suas hipóteses e, ao mesmo tempo, que a ação corporal (linguagens) se integre a essas palavras, pertença a esse ambiente de investigações matemáticas, pois procuram chegar ao significado de uma palavra através de outras palavras e linguagens. Dessa forma, a elaboração conceitual vai sendo gradualmente construída.

O episódio 1 evidencia todo um movimento dialógico em que os alunos buscam conjuntamente refletir sobre o padrão. Observa-se uma ação responsável, ética, intencional, ocorrida em meio a argumentações, pois cada pergunta e resposta era intencionalmente refletida. Havia nesse momento um ambiente de pertença, uma ação reflexiva em torno da tarefa, da palavra.

\section{Palavras finais}

O letramento está pautado em uma cultura social de aula de matemática, em que há uma intencionalidade no ato pedagógico, e professor e aluno caminham lado a lado, compartilham, dialogam, possuem objetivos, intenções, são responsáveis nesse espaço-tempo da sala de aula. Ou seja, esse não é um espaço e um tempo qualquer, mas um espaço-tempo planejado, dialógico, de pertença, de identidade; que traz a possibilidade de comunicar, ler, narrar em torno da linguagem matemática e da elaboração conceitual, o que provoca, em todo o grupo, experiências que podem ser renarradas e compartilhadas, pois se formam e se transformam pela ação da palavra.

As narrativas estabelecem em quem ouve ou lê momentos importantes de reflexões. As 
possibilidades que a narrativa abre nas aulas de matemática são trazidas pelo movimento das escritas dos alunos, pela argumentação e, levantamento de hipóteses em relação ao conceito matemático discutido, pelas sequências e tarefas e resolução de problemas. Narrar possibilita ação, em que autores e leitores se mobilizam a estabelecer proximidades, distanciamentos, relacionar, rememorar e conjecturar em relação à matemática. Observamos esse movimento acontecendo numa relação dialética de enlace, em que: narrar - falar, escrever, ler, ouvir e renarrar mobilizam no aluno um movimento de pertença ao texto e ao mundo.

\section{Referências}

BAKHTIN, M. M. (Volochinov). Marxismo e filosofia da linguagem: problemas fundamentais do método sociológico na ciência da linguagem. Trad. Michel Lahud, Yara F. Vieira, Lúcia T. Wisnik e Carlos Henrique D. Chagas Cruz. 9. ed. São Paulo: Hucitec, 1999.

FONSECA, M. C. F. R. Conceito(s) de numeramento e relações com o letramento. In: LOPES, C. E.; NACARATO, A. M. (Orgs.). Educação matemática, leitura e escrita: armadilhas, utopias e realidade. Campinas: Mercado de Letras, 2009.p.47-60. (Série Educação Matemática).

HIEBERT, J. et al. Making sense: teaching and learning mathematics with understanding. Portsmouth: Heinemann, 1997.

KLEIMAN, A. B. Modelos de letramento e as práticas de alfabetização na escola. In: KLEIMAN, A. B. (Org.). Os significados do letramento: uma nova perspectiva sobre a prática social da escrita. Campinas: Mercado de Letras, 1995, p.15-61.

KLEIMAN, A. B. Oralidade letrada e competência comunicativa: implicações para a construção da escrita em sala de aula. Scripta, Belo Horizonte, v.6, n.11, p.23-38, 2 sem. 2002. Disponível em:http://www.ich.pucminas.br/cespuc/Revistas_Scripta/Scripta11/Conteudo/N11_Sumario.p df. Acesso em: 6 jan.2016.

KLEIMAN, A. B. Preciso "ensinar" o letramento? não basta ensinar a ler e a escrever? Brasília / Campinas: Ministério da Educação. Cefiel/IEL. Unicamp, 2005-2010. (Coleção Linguagem e letramento em foco linguagem nas séries iniciais). Disponível em:

http://www.iel.unicamp.br/cefiel/alfaletras/biblioteca_professor/arquivos/5710.pdf. Acesso em: 9 nov.2015.

KLEIMAN, A. B. Letramento e suas implicações para o ensino de língua materna. Signo, Santa Cruz do Sul, v.32, n.53, p.1-25, dez. 2007. Disponível em:

http://www.letramento.iel.unicamp.br/publicacoes/artigos/Letramento_e_implicacoes_Kleima n.pdf Acesso em: 6 jan.2016. 
NACARATO, A. M. A escrita nas aulas de matemática: diversidade de registros e suas potencialidades. Leitura: Teoria \& Prática, Campinas, v.31, n.61, p.63-79, nov.2013. Disponível em: http://Itp.emnuvens.com.br/Itp/article/view/196 Acesso em: 28 dez. 2015.

NACARATO, A. M.; LUVISON, C. C. Educação matemática nos anos iniciais do ensino fundamental: possibilidades de produção do conhecimento científico. In: TAUCHEN, G.; SILVA, J. A.; SCHWANTES, L. Educação científica: pesquisas e experiências. Curitiba: CRV, 2015, p.3351.

PEREIRA, L. M. No centenário do nascimento de Paul Ricoeur: a memória como espaço de experiência e horizonte de espera. Diacrítica[online], v.27, n.2, p.175-192, 2013. ISSN 08078967. Disponível em: http://www.scielo.mec.pt/scielo.php?pid=S080789672013000200011\&script=sci_abstract Acesso em: 2 ago. 2015.

RICOEUR, P. Do texto à ação: ensaios de hermenêutica II. Porto: Rés, 1989.

RICOEUR, P. Tempo e narrativa. Tomo I. Campinas: Papirus, 1994.

RICOEUR, P. Tempo e narrativa. Tomo III. Campinas: Papirus, 1997.

SIRGADO, A. P.O social e o cultural na obra de Vigotski. Educação \& Sociedade, ano 21, n.71, jul. 2000. Disponível em: http://www.scielo.br/pdf/es/v21n71/a03v2171.pdf Acesso em: 17 out. 2015.

STREET, B. Perspectivas interculturais sobre letramento. Filologia Linguística Portuguesa, São Paulo, n.8, p.465-488, 2006. Disponível em: http://docplayer.com.br/12616208-Perspectivasinterculturais-sobre-o-letramento.html Acesso em: 25 jun.2014.

VIGOTSKI, L. S. A construção do pensamento e da linguagem. Trad. Paulo Bezerra. 2. ed. São Paulo: Martins Fontes, 2009.

VIGOTSKI, L. S. Imaginação e criatividade na infância. Trad. João Pedro Fróis. São Paulo: WMF Martins Fontes, 2014.

Recebido em setembro de 2019.

Aprovado em dezembro de 2019. 